\title{
РЕЗУЛЬТАТЫ КОМПЬЮТЕРНОГО МОДЕЛИРОВАНИЯ ПРОХОЖДЕНИЯ МАКСИМАЛЬНЫХ РАСХОДОВ РЕДКОЙ ПОВТОРЯЕМОСТИ В РУСЛЕ РЕКИ АЛЬМА
}

\author{
Т. С. Пономаренко, А.Н. Рыжаков
}

Российский научно-исследовательский институт проблем мелиоращии, Россия

\author{
Поступила в редакциюю 23 апреля 2018 г.
}

\begin{abstract}
Аннотация: Целью данного исследования являлось прогнозирование прохождения максимальных паводков редкой повторяемости - 0,5 и 3,0\% обеспеченности стока, на реке Альма, одной из крупнейших рек Крымского полуострова. В результате расчета для каждого момента времени в пределах заданного периода моделирования были определены расходы и уровни, а также скорости водного потока. Было определено плановое положение зоны затопления, а также площади затопления пяти населенных пунктов, ранжированные по обеспеченности стока для $3 \%-0,33$ км$^{2}$, для $0,5 \%-$ 0,18 км$^{2}$. Полученные результаты уверенно говорят о том, что морфометрия реки Альма (русло и пойменная территория) такова, что в случае неблагоприятных погодных условий (ливней и таяния снега) в русле очень быстро формируются значительные дождевые паводки, которые в итоге создают угрозу подтопления для расположенных ниже по течению населенных пунктов и объектов экономики. Это обуславливает необходимость создания системы оповещения населения, чтобы обеспечить возможность жителям подготовиться к паводку или уйти из опасной зоны, а службе спасения оперативно прибыть в зону предполагаемой чрезвычайной ситуации.
\end{abstract}

Ключевые слова: река Альма, бассейн реки, русловые участки, водохозяйственный комплекс, орошение, водоснабжение.

Abstract: The aim of this study was to predict the passage of maximum floods of rare repeatability 0.5 and $3.0 \%$ of the flow, on the river Alma, one of the largest rivers of the Crimean Peninsula. As a result of the calculation for each moment of time within the specified modeling period were determined water flow rates, water levels and water velocity. The planned position of the flood zone, as well as the areas of flooding of five settlements, ranked by flow security for $3 \%-0.33 \mathrm{~km}^{2}$, for $0.5 \%-0.18 \mathrm{~km}^{2}$, was determined. The obtained results confidently indicate that morphometry of the river Alma (channel and floodplain area) is such that in case of adverse weather conditions (rainfalls and snowmelt) significant rain floods are formed in the channel very quickly, which eventually create a threat of flooding for downstream settlements and economic facilities. This necessitates the creation of a system of alerting the public to provide an opportunity for the residents to prepare for flooding or to leave the danger zone and rescue service to arrive quickly in the area of the proposed extremal situation.

Key words: the Alma River, the river basin, run-of-river stations, water utilization system, irrigation, water supply.

\section{Введение}

Разработка эффективных превентивных мероприятий является одной из главных задач современной науки, изучающей наводнения и паводки. Надежное их прогнозирование требует определение объема, временных параметров, скорости русловых потоков на всем протяжении реки. Одним из способов получения таких данных является компьютерное моделирование.

(C) Пономаренко Т.С., Рыжаков А.Н., 2019
Наиболее скоротечные и быстроразвивающиеся паводки, наносящие наибольший ущерб вследствие внезапности, бывают на горных реках. Рассмотрим вероятность таких явлений на реке Альма.

Река Альма - одна из крупнейших рек Крымского полуострова. Она принадлежит к бассейну Черного моря и берет начало у подножия самого высокого массива Бабуган яйлы в Крымском природном заповеднике от слияния рек Бабуганки и Сары-Су. Альма, протяженность которой состав- 
ляет 84 км, является третьей по длине рекой Кры-

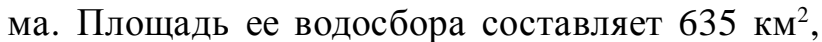
среднемноголетний расход реки $-1,2 \mathrm{~m}^{3} / \mathrm{c}$, а объем годового стока - 37,5 млн м 334,8$]$.

В верховьях в Альму со стороны левого берега впадает река Сухая Альма (длина 10 км), с правого - Коса (11 км) и Мавля ( 8,1 км). Ниже по течению долина Альмы значительно расширяется вплоть до Карагачской балки, где склоны долины опять сильно сближаются. Река пересекает Внутреннюю горную гряду. В пределах второй продольной долины слева в Альму впадает очень бурная во время паводков река Бодрак (длина - 17 км, площадь водосбора - 74,4 км²). В нижнем течении долина Альмы постепенно сужается. Приближаясь к морю, вновь расширяется. Здесь река принимает один левый приток - немноговодную балку Эски-Кышав, длина которой составляет 12 км [3].

В нижнем течении уклон реки к морю небольшой. Поэтому устье реки топко, берега поросли тростником, камышом и другими болотными растениями. Впадает Альма в Каламитский залив Черного моря севернее мыса Керменчик у села Песчаное [6].

Питание реки смешанное: снеговое, грунтовое и ливневое. Весеннее половодье начинается в марте, достигая максимального значения в апреле. Паводки наступают чрезвычайно быстро, уровни воды увеличиваются значительно. Поэтому размывы и наводнения иногда принимают характер стихийных бедствий [5].

\section{Материалы и методы}

Для оценки возможных негативных последствий при прохождении максимальных расходов редкой повторяемости $(0,5$ и $3 \%$ обеспеченности стока) был выполнен комплекс работ, включающий создание цифровой модели рельефа и разработку гидродинамической модели.

Для создания модели поверхностей и решения задач пространственного анализа использовался программный комплекс Autodesk c такими модулями как «Infraworks» и «Autocad Civil 3D».

При построении цифровой модели рельефа в качестве основы использовались высотные данные радарной топографической съемки SRTM-3 (Shuttle radar topographic mission) [7]. Построение поверхности осуществлялось с помощью модуля «Infraworks» путем импорта набора растровых изображений и дальнейшего экспорта в модуль «Autocad Civil 3D» полученной цифровой модели рельефа (ЦМР) $[2,4]$. Созданная ЦМР представля- ет собой цифровую поверхность, основой для которой является сетка точек с шагом 90,5 на 137,3 м.

На основе ЦМР подготовлены исходные данные (поперечные профили русла реки с заданным шагом) для разработки системы математических моделей, позволяющих рассчитать прохождение максимальных расходов редкой повторяемости [1].

Цифровая гидродинамическая компьютерная модель (ЦГКМ) прохождения максимальных расходов редкой повторяемости разработана с применением системы одномерных уравнений Сен-Венана (уравнения мелкой воды) [9] для участка реки Альма от населенного пункта Малиновка до устья (общей протяженностью 40 км).

\section{Результаты и обсуждения}

Для разработки цифровой гидродинамической компьютерной модели (ЦГКМ) для участка реки Альма от населенного пункта Малиновка до устья была использована следующая информация: 1) спутниковый снимок исследуемого участка; 2) цифровая модель рельефа местности; 3 ) русловые и пойменные поперечные сечения (42 поперечных сечения); 4) временные ряды максимальных расходов $0,5 \%$ и $3 \%$ обеспеченности стока [10].

Для создания модели были выполнены последовательные действия: 1) в файле речной сети выполнена координатная привязка космоснимка и нанесена ось русла реки; 2) на основе ЦМР сформированы в табличном виде координаты $(\mathrm{X}, \mathrm{Z})$ пойменных поперечных сечений (42 поперечных сечений); 3) в разделе морфометрических данных определено местоположение и параметры поперечных сечений русловой и пойменной части моделируемого участка; 4) выполнена привязка поперечных сечений, расположенных в населенных пунктах к продольному профилю расчетного участка; 5) в разделе гидродинамических параметров определена шероховатость пойменной части русла; 6) заданы граничные условия модели в виде сосредоточенного притока в нулевом пикете (равного максимальному расходу сбросного сооружения Партизанского водохранилища), распределенной проточности с правого и левого водосборов и уровня воды в концевом пикете; 7) установлен временной интервал моделирования с шагом расчета в 1 час; 8) выполнены расчеты для двух сценариев прохождения максимальных расходов редкой повторяемости.

Проведены сценарные исследования ЦГКМ и выявлены места возникновения чрезвычайных ситуаций при прохождении максимальных расхо- 


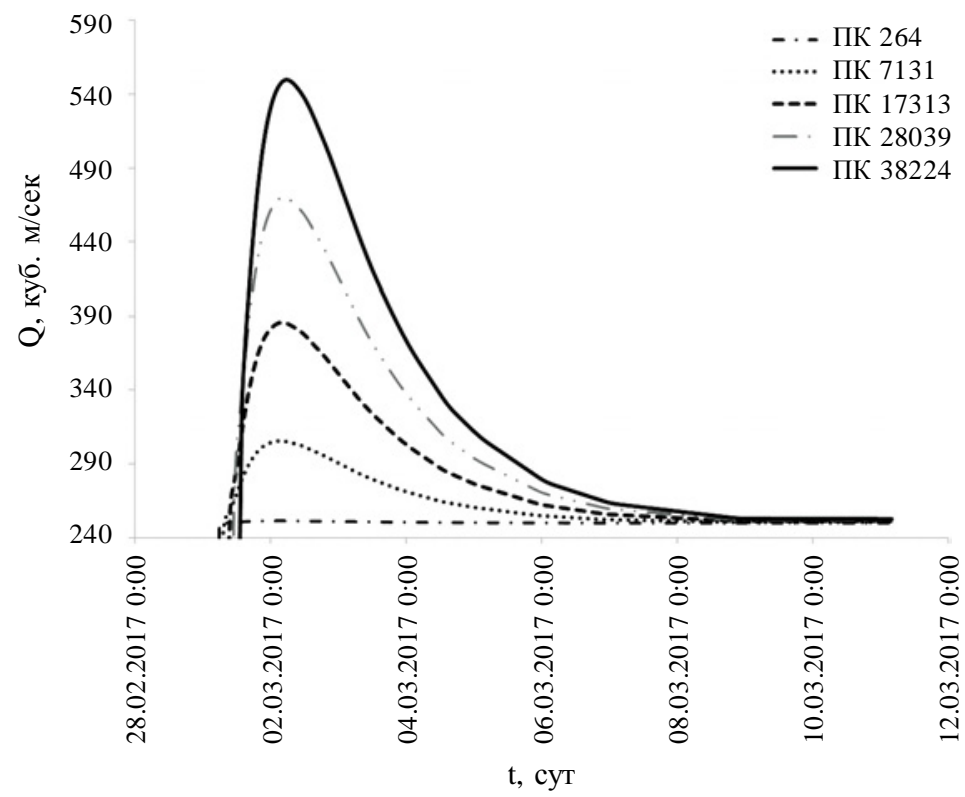

Puc. 1. Графики прохождения максимальных расходов при $0,5 \%$ обеспеченности стока

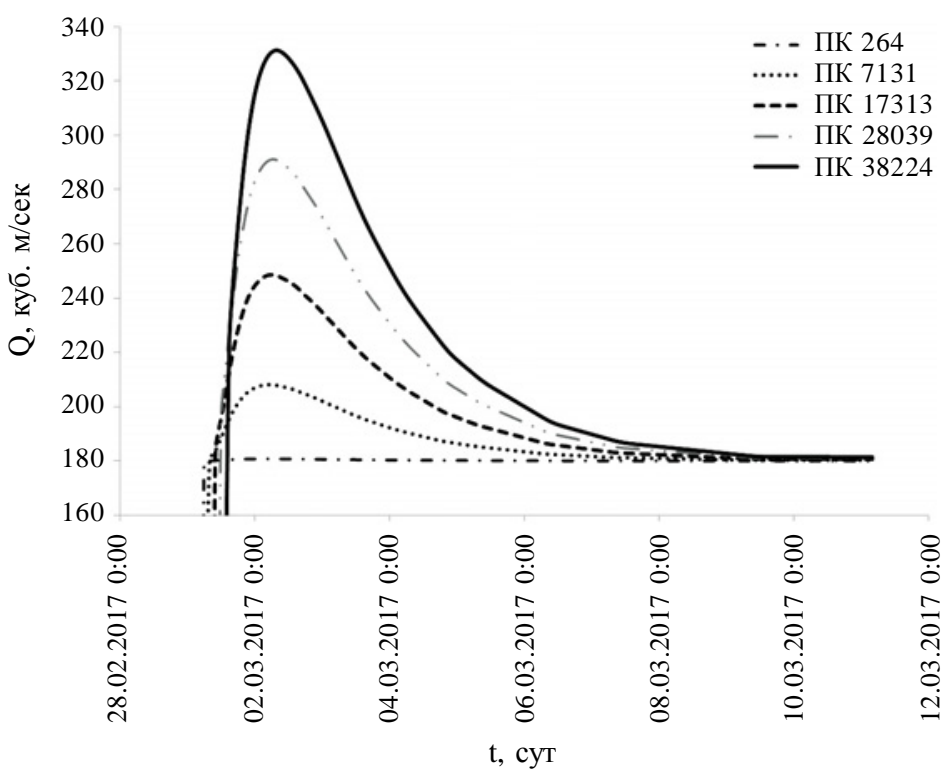

Puc. 2. Графики прохождения максимальных расходов при $3 \%$ обеспеченности стока

дов редкой повторяемости $0,5 \%$ и $3 \%$ обеспеченности стока.

В результате анализа полученных моделей на 0,5\% и $3 \%$ вероятности превышения стока на исследуемом участке реки Альма были установлены максимальные уровни воды в поперечных сечениях и на продольном профиле, динамика расходов и скоростей течения в расчетных точках на всем протяжении моделируемого участка (рис. 13), а также определены границы затопления пойменной территории в случае максимальных расходов $0,5 \%$ и $3 \%$ вероятности превышения стока.
В целях определения размеров вероятного вреда, который может быть причинен в результате чрезвычайной ситуации на основе результатов сценарных исследований определены зоны затопления и установлены их площади.

Наибольший уровень воды независимо от рассмотренной обеспеченности стока согласно полученному в результате моделирования графику наблюдается на ПК225 в районе населенного пункта Каштаны перед мостовым сооружением.

Наибольшие расходы согласно графикам, представленным на рисунках 1-2, наблюдаются через 


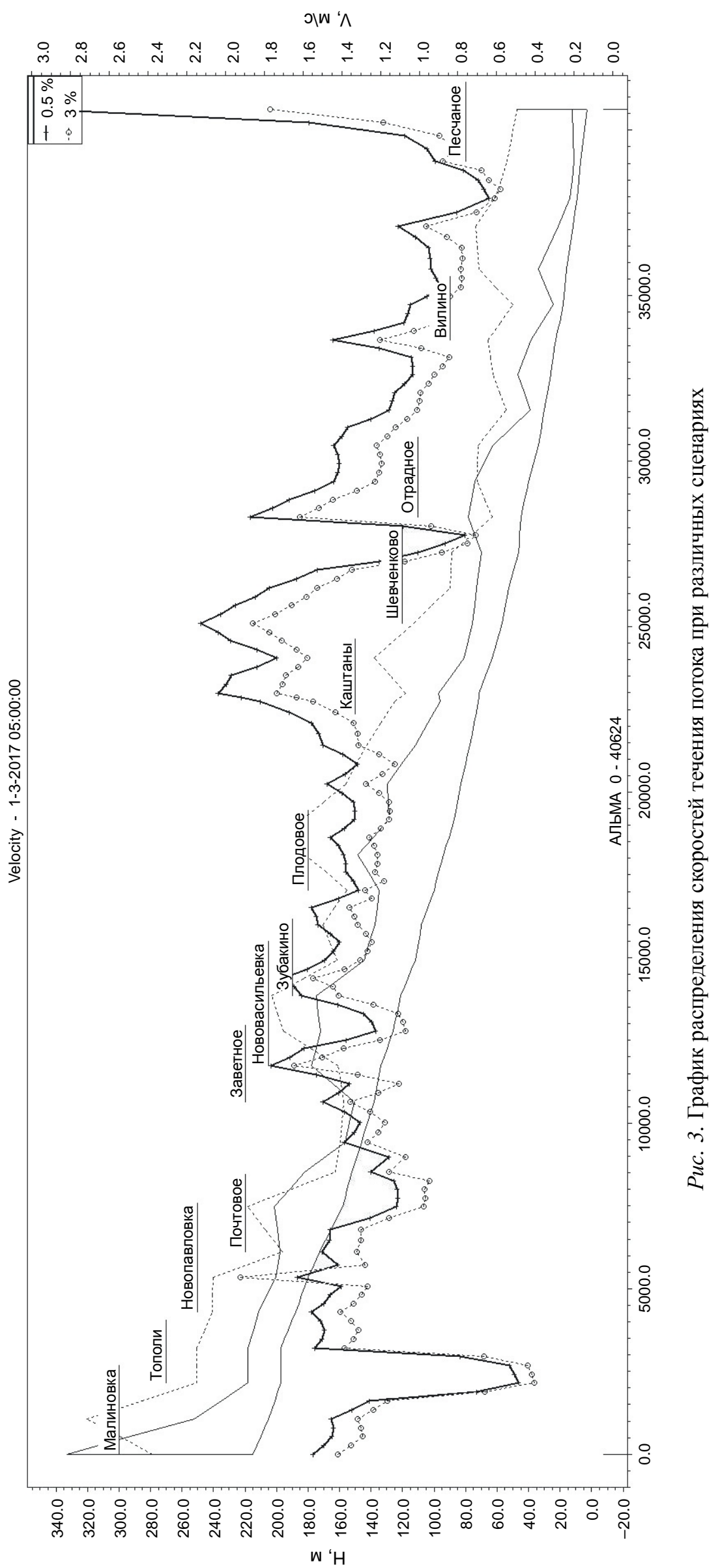


Площади затопления, ранжированные по обеспеченности стока

\begin{tabular}{|c|c|c|}
\hline \multirow{2}{*}{ Обеспеченность стока } & $\begin{array}{c}\text { Площадь затопления } \\
\text { пойменной части }\end{array}$ & $\begin{array}{c}\text { Площадь затопления } \\
\text { населенных пунктов }\end{array}$ \\
\cline { 2 - 3 } & км $^{2}$ & км $^{2}$ \\
\hline $0,5 \%$ & 8,38 & 0,33 \\
\hline $3 \%$ & 5,94 & 0,18 \\
\hline
\end{tabular}

32 часа с момента начала паводка. Максимальный расход при $3 \%$ обеспеченности стока составляет $185 \mathrm{~m}^{3} / \mathrm{c}($ ПК $394+47,3)$, а при $0,5 \%-310 \mathrm{~m}^{3} / \mathrm{c}$ (ПК402+31,8).

Максимальные скорости водного потока отмечены на участке русла между населенными пунктами Каштаны и Шевченко (ПК255). Скорость при $3 \%$ обеспеченности стока составляет $1,5 \mathrm{~m} / \mathrm{c}$, а при $0,5 \%-1,8 \mathrm{~m} / \mathrm{c}$.

Основным морфологическим параметром одномерной гидродинамической модели являются поперечные сечения реки. Для определения границ зон затопления из модели была получена максимальная отметка уровня воды и плановое положение границ вероятного затопления на заданную обеспеченность в каждом поперечном сечении. Данное расстояние с учетом рельефа и максимальной отметки уровня воды было вынесено в соответствии с местоположением поперечника в план. Методом интерполяции были определены и нанесены на картографическую основу границы вероятных зон затопления.

Согласно полученным границам зон затопления наводнению могут быть подвержены следующие населенные пункты: Новопавловка, Заветное, Плодовое, Каштаны и, в наибольшей степени, Песчаное. В таблице представлены площади возможного затопления при прохождении максимальных расходов редкой повторяемости.

Итак, полученные результаты уверенно говорят о том, что морфометрия реки Альма (русло и пойменная территория) такова, что в случае неблагоприятных погодных условий (ливней и таяния снега) в русле очень быстро формируются значительные дождевые паводки, которые в итоге создают угрозу подтопления для расположенных ниже по течению населенных пунктов и объектов экономики. Это обуславливает необходимость создания системы оповещения населения, чтобы обеспечить возможность жителям подготовиться к паводку или уйти из опасной зоны, а службе спасателей оперативно прибыть в зону предполагаемой чрезвычайной ситуации.
Для уточнения полученных результатов необходимы дополнительные изыскания. В частности, проведение подробной топографической съемки по всему руслу реки на расстояние, по профилю превосходящее максимальную зону наводнения, для корректировки расчетов уровня и потока в заданной точке русла. Расчетные характеристики необходимо сравнить с реальными измерениями уровня стационарными уровнемерами, то есть многократно проверить в реальных условиях стока.

\section{СПИСОК ЛИТЕРАТУРЫ}

1. Афонин Л. А. Проблемы прогнозирования паводков и наводнений / Л. А. Афонин // Наука. Инновации. Технологии. - Ставрополь, 2014. - № 1. - С. 31-39.

2. Бреева А. В. Современные подходы для получения морфометрических характеристик водосборов / А. В. Бреева // Пути повышения эффективности орошаемого земледелия. - 2016. - № 3 (63). - С. 45-49.

3. Доклад о состоянии и охране окружающей среды на территории Республики Крым в 2015 году / Министерство экологии и природных ресурсов Республики Крым. - Симферополь : ИП Бондаренко Н. Ю., 2016. -294 c.

4. Иванов В. А. Оценка пространственно-временной изменчивости поверхностного стока Крыма (гидравлическая модель) / В. А. Иванов, А. В. Прусов // Экологическая безопасность прибрежной и шельфовой зон и комплексное использование ресурсов шельфа. 2005. - № 13. - C. 126-150.

5. Крым: Река Альма. [Электронный ресурс]. URL : http://vkrumy.com/reki-i-vodopady/67-alma/.

6. Олиферов А. Н. Реки и озера Крыма / А. Н. Олиферов, 3. В. Тимченко. - Симферополь : Доля, 2005. $216 \mathrm{c}$.

7. Панорама карты покрытия SRTM [Электронный pecypc]. - URL : http://www.viewfinderpanoramas.org/ Coverage\% 20map\%20viewfinder panoramas_org3.html

8. Поверхностные водные объекты Крыма. Управление и использование водных ресурсов : справочник / А. А. Лисовский [и др.]; под ред. А. А. Лисовского. Симферополь : Крымучпедгиз, 2011. - 242 с.

9. Сенчуков Г. А. Применение компьютерного моделирования режимов водопотребления и водораспределения для повышения эффективности организации водопользования на оросительных системах / Г. А. Сенчуков, Т. С. Пономаренко // Пути повышения эффек- 
тивности орошаемого земледелия. - 2016. - № 4(64). C. 27-31.

10. Тищенко А. И. Рациональное использование водных ресурсов Крыма для целей мелиорации / А. И. Тищенко, А. А. Кузьмичев, Т. С. Пономаренко // Научный журнал Российского НИИ проблем мелиорации. - 2018. - № 1(29). - С. 188-207.

\section{REFERENCES}

1. Afonin L. A. Problemy prognozirovaniya pavodkov i navodneniy / L. A. Afonin // Nauka. Innovatsii. Tekhnologii. - Stavropol', 2014. - № 1. - S. 31-39.

2. Breyeva A. V. Sovremennyye podkhody dlya polucheniya morfometricheskikh kharakteristik vodosborov / A. V. Breyeva // Puti povysheniya effektivnosti oroshayemogo zemledeliya. - 2016. - № 3 (63). - S. 45-49.

3. Doklad o sostoyanii i okhrane okruzhayushchey sredy na territorii Respubliki Krym v 2015 godu / Ministerstvo ekologii i prirodnykh resursov Respubliki Krym. - Simferopol' : IP Bondarenko N. YU., 2016. - 294 s.

4. Ivanov V. A. Otsenka prostranstvenno-vremennoy izmenchivosti poverkhnostnogo stoka Kryma (gidravlicheskaya model') / V. A. Ivanov, A. V. Prusov // Ekologicheskaya bezopasnost' pribrezhnoy i shel'fovoy zon i kom-

\section{Пономаренко Таисия Сергеевна}

научный сотрудник Федерального государственного бюджетного научного учреждения «Российский научно-исследовательский институт проблем мелиорации», г. Новочеркасск, т. (8635) 26-65-00, E-mail: rosniipmovpvapk@yandex.ru

Рыжаков Алексей Николаевич

научный сотрудник Федерального государственного бюджетного научного учреждения «Российский научно-исследовательский институт проблем мелиорации», г. Новочеркасск, т. (8635) 26-65-00, E-mail: xrust.89@bk.ru pleksnoye ispol'zovaniye resursov shel'fa. -2005. - № 13 . -S. 126-150.

5. Krym: Reka Al'ma. [Elektronnyy resurs]. - URL : http://vkrumy.com/reki-i-vodopady/67-alma/.

6. Oliferov A. N. Reki i ozera Kryma / A. N. Oliferov, Z. V. Timchenko. - Simferopol' : Dolya, 2005. - 216 s.

7. Panorama karty pokrytiya SRTM [Elektronnyy resurs]. - URL: http://www.viewfinderpanoramas.org/Coverage map viewfinder panoramas_org3.html

8. Poverkhnostnyye vodnyye ob"yekty Kryma. Upravleniye i ispol'zovaniye vodnykh resursov : spravochnik / A. A. Lisovskiy [i dr.]; pod red. A. A. Lisovskogo. - Simferopol' : Krymuchpedgiz, 2011. - 242 s.

9. Senchukov G. A. Primeneniye komp'yuternogo modelirovaniya rezhimov vodopotrebleniya i vodoraspredeleniya dlya povysheniya effektivnosti organizatsii vodopol'zovaniya na orositel'nykh sistemakh / G. A. Senchukov, T. S. Ponomarenko // Puti povysheniya effektivnosti oroshayemogo zemledeliya. - 2016. - № 4(64). - S. 27-31.

10. Tishchenko A. I. Ratsional'noye ispol'zovaniye vodnykh resursov Kryma dlya tseley melioratsii / A. I. Tishchenko, A. A. Kuz'michev, T. S. Ponomarenko // Nauchnyy zhurnal Rossiyskogo NII problem melioratsii. - 2018. № 1(29). - S. 188-207.

Ponomarenko Taisia Sergeevna

Researcher of the Federal State Budgetary Scientific Institution «Russian research Institute of melioration problems», Novocherkassk, tel. (8635) 26-65-00, E-mail: rosniipmovpvapk@yandex.ru

Ryzhakov Aleksey Nikolayevitch

Researcher of the Federal State Budgetary Scientific Institution «Russian research Institute of melioration problems», Novocherkassk, tel. (8635) 26-65-00, E-mail: xrust.89@bk.ru 